\title{
Learning Strategies in Elementary Schools During COVID-19 Pandemic in North Sulawesi
}

\author{
Asep Supena ${ }^{1, \mathrm{a}}$, Deane Umboh ${ }^{2, \mathrm{~b}}$, Deysti Trifena Tarusur,c, Jeane Kalengkongan ${ }^{2, \mathrm{~d}}$ \\ ${ }^{1}$ Jakarta State University \\ ${ }^{2}$ Manado State University \\ a asepsupena@unj.ac.id ${ }_{\text {d }}^{\text {bdeane.umboh@gmail.com }}, \underline{\text { deystitarusu@gmail.com }}$, \\ jeanepray_mk@yahoo.com
}

\begin{abstract}
The psychological impact of physical distancing experienced by teachers and students during the COVID-19 pandemic. The quality of teacher and student relations in learning interactions does not proceed as usual. Various learning strategies strived for teachers to remain productive and professional in carrying out their duties as a teacher and educator. Teacher strategies adapted to the places and conditions of each region has its uniqueness. The learning strategy undertaken by the teacher is influenced by the family spirit that is the hallmark of the Indonesian nation's culture. This study aims to explore the experience of elementary school teachers and analyze the level of participation and supporting factors and constraints experienced by teachers, in implementing learning strategies for elementary school students during COVID-19 pandemic in North Sulawesi. A total of ten teachers who live in rural areas and five teachers who live in urban areas narrate their experiences related to learning strategies in this pandemic period. Teachers in rural areas are more involved than teachers in urban areas, because the number of elementary schools in North Sulawesi is mostly in rural areas. Data was collected using semi-structured interview techniques and analyzed using narrative content analysis. The results of the analysis found that the learning strategy by visiting students directly at home is done by teachers in rural areas because of the shorter distance and relatively short travel time to visit students' homes. Whereas the strategy carried out by teachers in urban areas was more dominant carried out by utilizing virtual facilities through interactions via smartphones and learning with internet-based applications.
\end{abstract}

Keywords: Learning strategies, elementary school, COVID-19 pandemic

\section{INTRODUCTION}

Physical distancing, stay at home and work from home implemented during the COVID-19 pandemic, affect the quality of relations between people. During this pandemic, the government adopted such a policy to limit physical interaction between people to suppress the spread of co-19. This conditions the community to maintain distance and reduce the intensity of physical relationships with others. 
In the development of human culture from the beginning until now, the nature of dependence with fellow humans is very significant in influencing one's knowledge, attitudes, skills, and mentality. Humans are social creatures whose lives depend on others who need each other (Santoso, 2017). Some examples of the impact of someone who is experiencing a crisis of relations with others during this pandemic such as feelings of loneliness or social isolation, emotional instability, physical health disorders, etc (Hwang, et al. 2020; Loades et al., 2020).

After all the learning processes carried out at school, close relationships, greeting each other, meeting physically, embracing each other, shaking hands with the teacher and students, suddenly changed drastically with limited communication and relations. Not being able to meet physically, not shake hands with one another, is a new reality that was initially difficult for both teachers and students to experience. Moreover, such habits become a daily routine at school. Students who only spend time studying at home feel lonely because they can not meet with the teacher and his friends.

During the COVID-19 pandemic, teachers and students were not as intense in face-to-face meetings as usual. The learning process that is usually carried out in classrooms interactively between teachers and students, experiences obstacles in the middle of this pandemic. Before the pandemic, usually greeting activities, sitting together to share experiences into the daily life of teachers and students. The teacher embraces and reinforces with a touch to students. Students play happily with their friends. No divider limits students to joke, join hands with the teacher and his friend.

But such an atmosphere is very much different after this pandemic. Students begin to feel lonely playing alone at home, not getting direct guidance from the teacher to study at home. Other psychological effects experienced by teachers and students are very diverse and complex. Some teachers feel less productive in developing their teacher professionalism by working from home, and vice versa students are not motivated to study at home. There are sometimes misunderstandings related to teacher instructions to students, either through online, semi-online, or offline assignment communication. This affects the level of understanding of students and even parents who accompany at home. So it becomes a challenge for teachers to be able to transfer information that is meaningful to students.

Several learning strategies carried out to build teacher and student relations to minimize the impact as described above. The experiences of several teachers and students in dealing with the reduced quality of teacher and student relations, illustrate the importance of building quality relationships between teachers and students during the pandemic as an effort to address the psychological impact caused by this pandemic and create an atmosphere that conditions students and teachers to be able to continue the learning process even outside the classroom.

Learning strategies tailored to the needs and conditions to build relationships quality and minimize the psychological impact that weakens the quality of teacher and student relations. Besides, the strategies undertaken by the teacher aim to teach students related subject matter that is poorly understood, educate and equip students in developing life skills, character building, and the socialization of healthy ways of life as an effort to prevent disease. Learning strategies oriented to the quality of teacher-student relations also carried out to make the work and study program a success from home, in response to being actively involved in breaking the chain of the spread of Covid-19, with the spirit of kinship and cooperation which is the culture of the Indonesian nation (Majid, 2020; Slikkerveer, 2019).

This study aims to explore the experience of elementary school teachers and analyze the level of participation and supporting factors and constraints experienced by teachers, in implementing learning strategies for elementary school students in North Sulawesi. 


\section{LITERATURE REVIEW}

In learning in elementary schools, the role of the teacher is very influential for students' readiness to learn. Teachers must design learning that is attractive and following the characteristics of students so that learning objectives to do achieved. Student-centered learning strategies are expected to increase student activity in the learning process and can improve student learning outcomes (Goodman, Barker, \& Cooke, 2018; Şahin, Harun. Ö, Muhammed. A, 2020). The learning strategy designed by the teacher based on the need to process learning activities (Anam \& Stracke, 2016). Especially during this pandemic, an unusual learning strategy needed. Strategies of learning designing specifically to suit the conditions of teachers and students. That requires more thinking and implementation seriously because it has both positive and negative impacts.

Some research related to education and learning in the pandemic period has carried out. Among the studies conducted Viner, et al to identify and know the effectiveness of school closures and the practice of maintaining distance at other schools during this COVID-19 outbreak (Viner et al., 2020). P.Research conducted by Purwanto, et al, to obtain information about the performance of teachers in SD Tangerang, the results of this study found several advantages and disadvantages in the Work From Home program (Purwanto et al., 2020). Furthermore, research on the impact of social psychology due to this pandemic(Agung, 2020). Likewise, the influence of the COVID-19 pandemic on the implementation of online learning in elementary schools and universities (Dewi, 2020; Firman \& Rahayu, 2020).

The attention given by the teacher is very instrumental in the emotional development of students. These shown by students expressing feelings of pleasure, both in words and from the attitude shown by students (Obergriesser \& Stoeger, 2020; Riley, 2011). Also, developments in the self-introduction and social life of students will develop (Franks, 2010; Kalkhoff, Thye, \& Pollock, 2016). Teacher learning strategies during the pandemic certain involve the role of parents to supervise and monitor student learning at home. The family becomes the basis in the introduction of children's moral and cultural values, attitudes, and habits, which affect children's social life.

Family conditions play a significant role in children's development cognitive, affective, psychomotor even mentally, and in social life and self-intimacy (Santrock, 2011). Therefore the process of learning from home accompanied by parents will strengthen the relationship between parents and children. Likewise, the process of learning from home accompanied by parents will reinforce parent and child relations. Also, parents in assisting children learn at home need the motivation and success of children's learning (Đurišić \& Bunijevac, 2017).

In this study, the theory review adjusted to the type and purpose of narrative research. Theory in narrative research is a perspective or an ideological guide that provides a structure to support research subjects and reports. The reason for narrative research is to minimize the use of literature and focus on the experiences of participants (Adler, Lodi-Smith, Philippe, \& Houle, 2015; Hegde, Tungesh, 2016).

\section{RESEARCH METHODOLOGY}

This research is a qualitative study using a narrative research design. The narrative research style to implemented in problems regarding the experience of teachers in pursuing learning strategies, which carried out to build teacher relationships with students during the COVID-19 pandemic. Narrative research is helpful in various domains of sociology, anthropology, history, nursing, psychology, and communication studies to get full insights about people's life experiences, especially teachers (Elçi \& Devran, 2014; Mon, 2020).

Participants in this study involved elementary school teachers in several areas of North Sulawesi, namely ten teachers from rural areas and five teachers from urban areas. Teachers in rural 
areas are more involved than teachers in urban areas, because the number of elementary schools in North Sulawesi is mostly in rural areas.Participants were selected using a purposive sampling technique in which elementary school teachers deliberately selected with characteristics by the research objectives (Liamputtong, 2019). A relatively small sample to take to increase the depth of meaning of a problem or information needed in research because what matters is the quality of research, not the quantity (Campbell et al., 2020).

Participants shared experiences narrated about learning strategies undertaken in teaching in elementary schools, during the COVID-19 pandemic period and their strengths and weaknesses. According to Sikes and Gale (Mendieta, 2013), narrated stories manifest human nature that reflects how humans position socially and culturally in their world.

Data collection techniques well done through semi-structured interview methods for participants and documentation. Narrative content analysis techniques originating from participants carried out to gain a deepened insight into the psychological impact and strategies of building teacher-student relations during the COVID-19 pandemic. Through content analysis, two themes found that would help in reaching further conclusions.

\section{FINDING AND DISCUSSION}

In conducting research, researchers conducted semi-structured interviews equipped with documentation. Each teacher narrates personal experience in learning strategies during the COVID19 pandemic. Each teacher from various elementary school backgrounds in the context of the COVID-19 pandemic strives to continue to carry out their duties and responsibilities in educating and teaching elementary school students. There are differences in the level of participation among teachers. Through all the narratives provided, the researcher found two themes that organized and presented to explore and describe the story to get better analysis results.

Theme 1: Learning strategies to build teacher-student relations during the COVID-19 pandemic

This theme discusses learning strategies to build teacher and student relations in the context of the COVID-19 pandemic. The experience of the teacher as a participant has similarities and differences according to the school context, student characteristics, and the area of residence. Some teachers who live in rural areas and even in remote villages make a strategy of visiting students' homes with a variety of variations.

In general, teachers visit students concerning health protocols by washing hands before entering a student's home, still wearing a mask, and keeping a distance. There are even some teachers who visit until night because they have to rotate from one house to another. Besides, the teacher distributes basic needs, masks, and hand sanitizers to students in addition to bringing lesson assignments that students must do while studying at home. The purpose of the teachers visiting students' homes is to monitor the state of students in the learning process at home while instilling the attitude of care, cooperation, and discipline to maintain personal hygiene. Student responses include students who are happy to get a visit from the teacher. Students are enthusiastic about sharing their experiences studying at home and motivated to learn. Students also expressed their hope that teachers would often visit and teach at home,

But in the context of rural communities, many factors make quality learning from home unsuccessful. In general, parents (fathers) who work as farmers, have been to the garden since morning and returned in the afternoon. The mother acts as a housewife who takes care of the house and children. But with their busy days at home and low levels of education, parents (mothers) lack understanding of the subject matter from school. So that parents have difficulty teaching children at home. That affects children's learning motivation at home. So that children experience laziness and 
boredom to learn. Although relationships with parents and siblings at home are intimate, many children miss the atmosphere of learning at school. Especially with this pandemic condition.

Therefore, the teacher's strategy of visiting students' homes during this pandemic is psychologically very beneficial for students. Teachers who visit student homes can directly monitor the condition of students in their learning at home. The relationship between teacher and student maintained during this pandemic. In rural areas that have good internet coverage, teachers also combine interactions with students through direct visits or by using social media applications.

Furthermore, for teachers whose schools are in urban areas, and which are affordable by internet facilities, the learning strategy is carried out online. This strategy is carried out by the teacher by the recommendation of the local service that is to give a task that is not too heavy and does not burden students. The task given relates to the importance of maintaining health and the environment in pandemic conditions. Also, the teacher makes a short learning video to explain the material. The teacher builds relationships with students and relates to the zoom application, video calls, and WhatsApp groups. The domicile of students who are scattered and far apart, and it is not possible to visit the student's home.

The context of parents who live in urban areas, working fathers and mothers, makes many parents do their work at home. Although children are with their parents, their parents make them less likely to have the opportunity to teach children to learn. Besides, the work pressure from the office makes parents often emotionally facing children. So teaching children becomes an additional burden for parents.

In the context of the COVID-19 pandemic, teachers in urban areas are limited to make visits to student homes. But by utilizing technological advances, virtual interaction between teachers and students can be done. Students can use a smartphone or laptop. Besides, teachers can develop learning innovations by designing learning videos that are interesting for students. When interacting online with students, virtual relationships that done at least help teachers monitor the progress of student learning processes, although they still experience certain obstacles.

Based on the description above, the teacher's strategy in building relationships with students regarding the learning process adjusted to the conditions of residence and the status of the COVID19 distribution zone. In general, the strategy of visiting students' homes is carried out by teachers in many rural green zones where there are no citizens indicated by COVID-19. The next theme relates to the strengths and weaknesses of the strategies employed in building elementary school teacher and student relations.

Theme 2: Strengths and weaknesses of the strategy used in building teacher and student relations during the COVID-19 pandemic.

\section{Advantages}

The learning strategies are undertaken during the COVID-19 pandemic through visiting students' homes or virtually exceeding the advantages. The strategies of visiting a student's home make the atmosphere of interaction more real. Students and parents are happy with the teacher's home visit. Students can directly express what they are doing at home and convey what has become their difficulty in learning. This strategy shows the attention and concern of the teacher towards students during the pandemic, of course, by paying attention to health rules and protocols.

The interaction strategies of teachers and students virtually have advantages too. During this pandemic, psychological distancing expected to reduce the number of cases of COVID-19 patients. Online learning limits physical encounters in interaction but does not reduce the quality of learning as long as it is conducted with discipline by the teacher and students. Students are also happy with the virtual meeting that held. Furthermore, with virtual interaction, adding knowledge and insight for teachers and students regarding the development of technology and internet-based communication. 


\section{Deficiency}

In the application of learning strategies during this pandemic, many shortcomings also were found. The strategy of visiting students' homes directly, during the pandemic is more time-consuming and labor-intensive. The teacher must prepare and schedule a time to visit the student's home. The teacher also prepares with material/assignments that will be given to students. The teacher cannot visit all students in a day. Especially for teachers in remote rural areas who have to walk from one house to another. Other constraints when direct interaction, students show a spoiled attitude and do not want to learn because accompanied by parents (usually in low-grade students). In a short time, the teacher can teach students one material classically. But by visiting a student's house,

Furthermore, learning strategies with virtual interactions have disadvantages too. Students who study online usually loaned to their parents' smartphones or laptops. So students must follow learning after their parents finish their work. If there are siblings in one house, it will be difficult because of the limited smartphone/laptop to participate in learning activities (must take turns). The learning process no longer refers to the curriculum, and little material taught.

Another obstacle is that online meetings and learning are interrupted if the signal interrupted, causing miss communication. Quota supply is the student's complaint during online learning. In the context of parents' low economic background, some students do not have smartphones. So that only a portion of the total number of students can learn online. The implementation of online learning does not guarantee an assessment and evaluation of learning outcomes that are accurate and measurable. Even with virtual interactions, the learning process is not as effective as learning in a real class, because the time for learning is shorter.

\section{CONCLUSION AND FURTHER RESEARCH}

Based on the results of research and discussion, it concluded that the learning strategies used by elementary school teachers during the COVID-19 pandemic were to conduct home visits, strategies for combining home visits and online learning, and online learning strategies. Home visiting strategies are generally carried out by teachers in rural/remote areas, while online learning strategies are carried out by teachers in urban areas. Combining both strategies is done by rural and urban teachers. The learning strategies undertaken by each teacher have advantages and disadvantages, both from the subject matter that not maximally provided to students, psychological factors, learning facilities, and the accuracy of the results of the learning evaluation.

This study has limitations in the limited participation of participants, so it has not provided a general description for all elementary schools in the North Sulawesi region. Therefore, further research needs to do relating to learning strategies in elementary schools during the COVID-19 pandemic

\section{REFERENCES}

Adler, J. M., Lodi-Smith, J., Philippe, F. L., \& Houle, I. (2015). The Incremental Validity of Narrative Identity in Predicting Well-Being: A Review of the Field and Recommendations for the Future. Personality and Social Psychology Review. https://doi.org/10.1177/1088868315585068

Agung, I. M. (2020). Memahami Pandemi Covid-19 Dalam Perspektif Psikologi Sosial. Psikobuletin:Buletin Ilmiah Psikologi.

Anam, S., \& Stracke, E. (2016). Language learning strategies of Indonesian primary school students: In relation to self-efficacy beliefs. System, 60, 1-10. 
https://doi.org/10.1016/j.system.2016.05.001

Campbell, S., Greenwood, M., Prior, S., Shearer, T., Walkem, K., Young, S., ... Walker, K. (2020).

Purposive sampling: complex or simple? Research case examples. Journal of Research in Nursing. https://doi.org/10.1177/1744987120927206

Dewi, W. A. F. (2020). Dampak COVID-19 terhadap Implementasi Pembelajaran Daring di Sekolah Dasar. EDUKATIF: JURNAL ILMU PENDIDIKAN. https://doi.org/10.31004/edukatif.v2i1.89

Đurišić, M., \& Bunijevac, M. (2017). Parental involvement as a important factor for successful education. Center for Educational Policy Studies Journal.

Elçi, A., \& Devran, B. Ç. (2014). A narrative research approach: The experiences of social media support in higher education. Lecture Notes in Computer Science (Including Subseries Lecture Notes in Artificial Intelligence and Lecture Notes in Bioinformatics). https://doi.org/10.1007/978-3-319-07482-5_4

Firman, F., \& Rahayu, S. (2020). Pembelajaran Oñline di Tengah Pandemi Covid-19. Indonesian Journal of Educational Science (IJES). https://doi.org/10.31605/ijes.v2i2.659

Franks, D. D. (2010). Neurosociology: The nexus between neuroscience and social psychology. In Neurosociology: The Nexus Between Neuroscience and Social Psychology. https://doi.org/10.1007/978-1-4419-5531-9

Goodman, B. E., Barker, M. K., \& Cooke, J. E. (2018). Best practices in active and student-centered learning in physiology classes. Advances in Physiology Education. https://doi.org/10.1152/advan.00064.2018

Hegde, R., Tungesh, G. M. M. A., (2016). Exploring Teachers ' Perceptions with the Narrative Inquiry Approach. 16(July), 150-158. Retrieved from www.languageinindia.com

Kalkhoff, W., Thye, S. R., \& Pollock, J. (2016). Developments in Neurosociology. Sociology Compass. https://doi.org/10.1111/soc4.12355

Liamputtong, P. (2019). Handbook of Research Methods in Health Social Sciences. Handbook of Research Methods in Health Social Sciences, 1-2248. https://doi.org/10.1007/978-981-105251-4

Loades, M. E., Chatburn, E., Higson-Sweeney, at. al. (2020). Rapid Systematic Review: The Impact of Social Isolation and Loneliness on the Mental Health of Children and Adolescents in the Context of COVID-19. Journal of the American Academy of Child \& Adolescent Psychiatry. https://doi.org/10.1016/j.jaac.2020.05.009

Majid, N. (2020). Strategies for Strengthening Character Through Mappatulung Local Wisdom in Actualizing Pancasila Values in the Muara Badak Coastal Area. https://doi.org/10.2991/assehr.k.200417.020

Mendieta, J. A. (2013). Narrative research: An alternative approach to study language teaching and learning. Folios. https://doi.org/10.17227/01234870.37folios 135.147

Obergriesser, S., \& Stoeger, H. (2020). Students' emotions of enjoyment and boredom and their use of cognitive learning strategies - How do they affect one another? Learning and Instruction. https://doi.org/10.1016/j.learninstruc.2019.101285

Purwanto, A., Asbari, M., Fahlevi, M., Mufid, A., Agistiawati, E., Cahyono, Y., \& Suryani, P. (2020). Impact of work from home (WFH) on Indonesian teachers performance during the COVID19 pandemic: An exploratory study. International Journal of Advanced Science and Technology.

Riley, P. (2011). Attachment theory and the teacher-student relationship: A practical guide for teachers, teacher educators and school leaders (First Edit). New York: Routledge.

Şahin, H., \& Özkan, M. A. (2020). Investigation of the Learning Strategies of Pedagogical Formation Certificate Program Students in Terms of Some Variables. International Education Studies, 13(3), 18. https://doi.org/10.5539/ies.v13n3p18

Santoso, M. B. (2017). MENGURAI KONSEP DASAR MANUSIA SEBAGAI INDIVIDU MELALUI RELASI SOSIAL YANG DIBANGUNNYA. Prosiding Penelitian Dan Pengabdian Kepada Masyarakat. https://doi.org/10.24198/jppm.v4i1.14217

Santrock, J. . (2011). Child Development Thirteenth Edition (13th ed., Vol. 18). New York: McGrawHill. 
Sen, D. (2020). A Narrative Research Approach: Rural-Urban Divide in Terms of Participation in Digital Economy in India. 7(1), 42-51. https://doi.org/10.34218/JOM.7.1.2020.006

Slikkerveer, L. J. (2019). Gotong Royong: An Indigenous Institution of Communality and Mutual Assistance in Indonesia. https://doi.org/10.1007/978-3-030-05423-6_14

Viner, R. M., Russell, S. J., Croker, H., Packer, J., Ward, J., Stansfield, C., .. Booy, R. (2020). School closure and management practices during coronavirus outbreaks including COVID19: a rapid systematic review. The Lancet Child and Adolescent Health. https://doi.org/10.1016/S2352-4642(20)30095-X 